
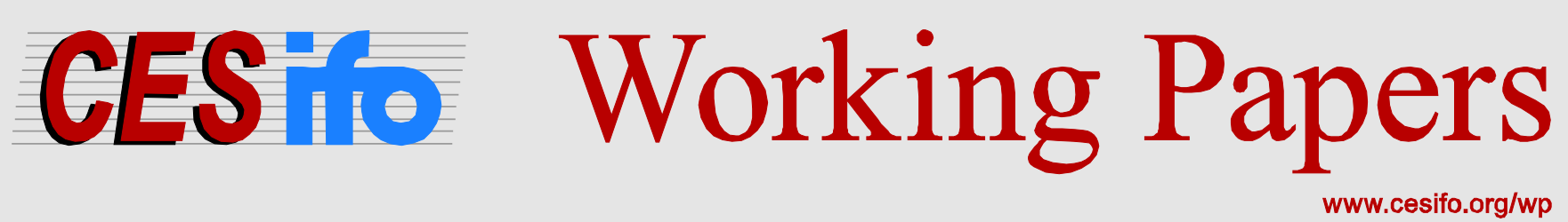

\title{
Anyone for Social Security Reform?
}

\author{
Partha Sen \\ CESIFO WORKING PAPER NO. 6035 \\ CATEgory 6: Fiscal Policy, MaCroeconomics and GrowTH \\ August 2016
}
An electronic version of the paper may be downloaded
- from the SSRN website:
- from the RePEc website:
- from the CESifo website:
www.SSRN.com
www.RePEc.org
www.CESifo-group.org/wp




\title{
Anyone for Social Security Reform?
}

\begin{abstract}
A reform of a pay-as-you-go social security makes the pensioners worse off and the working generations better off in the period of the reform (in a dynamically efficient economy without altruism). The observed reluctance across all age groups to support such reforms is usually explained by the insurance properties of these schemes. I propose an alternative in a two sector setting. Since the old consume labor-intensive goods like healthcare etc., the reform causes labor demand to fall and reduces wages. This effect could dominate the lower social security payments for the young. Thus both the young and old oppose the reform (that makes the unborn generations better off--the new steady welfare, with a higher capital stock, is higher).
\end{abstract}

JEL-Codes: H550.

Keywords: social security reform, two sector models, labor market.

Partha Sen

Centre for Development Economics

Delhi School of Economics

University of Delhi

India - 110007 Delhi

partha@econdse.org

I thank CESifo for hospitality during my visit to Munich in May 2016. Previous versions were presented at seminars at CESifo, Bath, Bolzano, Cardiff, Bank of Portugal, Villa Mondragone Conference, Rome, the IER Conference, Osaka and the Bank of Japan. I am indebted to Patrick Minford from saving from an egregious error; and Pedro Teles and Isabel Correia for helpful discussion. 


\section{INTRODUCTION}

Most advanced capitalist countries have problems with managing their social security systems. The social security system comprises of many schemes e.g. in the US it pays old-age pension, benefits to the disabled, and also survivor benefits to widows and children of deceased workers. ${ }^{\text {T }}$ The part of a social security system in need of urgent attention is the old-age pension scheme. The looming crisis is due to the longer lives of the retired, and a declining birth rate manifesting itself in the shrinking size of the labor force.

An unfunded public pension system or pay-as-you-go (PAYG) scheme provides insurance that private markets are unwilling to offer due to moral hazard and other reasons (Diamond (1977), (2004), Aaron (2011); Feldstein and Liebman (2002) provide a survey).Since the PAYG scheme is funded by a payroll tax, it has implications for labor supply. Moreover, since the working age population saves and invests, capital accumulation is also affected.

Economists, and other policy-makers, have looked at the "reform" of such system. A reform consists of a reduction of transfers from the working population (the “young”)to the retired (the "old”) in that period--indeed, there is talk of privatizing social security i.e. moving to a fully-funded system from the currently (predominantly) PAYG system.

A large literature exists that looks at the consequences of reforming a PAYG system. The three major themes highlighted above--viz. the crowding out of capital, risksharing across generations, and the distortion introduced in labor supply by using payroll taxes to finance the social security scheme-have been discussed at length ${ }^{\text {ii }}$ (see e.g. Boldrin and Rustichini (2000),Casamatta, Cremer and Pestieau (2000), Krueger and Kubler (2006), Fuster, Imrohoroglu and Imrohoroglu (2007), Nishiyama and Smetters

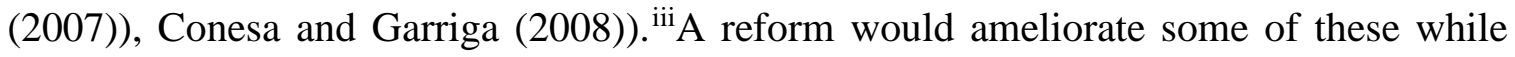
exacerbating others. A fair summary of this large literature would be to say that in a 
dynamically efficient economy, the absence of insurance markets is the main hurdle for the reform of such a system. ${ }^{\text {ivv }}$

In this paper we re-examine the macroeconomic aspect of social security reform in a dynamically efficient economy. And to focus on this issue, we assume away the other features of a PAYG system. In particular, there is no uncertainty, so insurance is not an issue; also, labor is supplied inelastically, and so the distortion in the labor-leisure choice is absent. Moreover, generations are not linked together by altruism.

In the Samuelson-Diamond overlapping generations model (Samuelson (1958), Diamond (1965)), following a reform, the disposable income of the young in that period increases (although they, in turn, would see reduced pension payment to them when they are old). ${ }^{\text {vi }}$ Capital accumulation increases. In a one-sector setting, the old in the period when the reform is introduced, lose by the full amount of the reduced transfer since the interest rate in that period is unchanged. And because they consume all their income, their consumption goes down by the full amount of the lowered social security benefits. The young gain (in a dynamically efficient setting) because their lifetime income goes up.

The reform is areneging on an implicit promise made by society to the currently old. This, no doubt, spurs capital accumulation but the old in the period of reform are paying the price for it. That the retirees would be opposed to a reform is self-evident but what about the working population? Should they not be marching down Champs Elysees or to the US Congress demanding reform?

In the United States, the social pension scheme continues to be the most popular government program. vii This popularity of the system among the working population requires explanation. We ask in this paper whether at any given date is it true, that in the absence of uncertainty, the interests of the young and the old are always implacably opposed to one another? And will a reform, while hurting the old, benefit the young? 
A strand of the literature seeks to explain the existence (and its continuation) of a social security system by appealing to worker's heterogeneous productivity. Low productivity workers, in anticipation of a social security receipt that is not (or at most imperfectly) correlated with their contribution to the PAYG system, vote with the retired (see Tabellini (2000), Casamatta, Cremer Pestieau (2000).; also Razin, Sadka and Swagel (2002)).

In this paper, I propose an explanation that does not rely on workers' productivities being different from each other. I use a two-sector set-up. Recently Robert Solow (2005) had lamented on the dearth of two-sector (or multi-sector) models in dynamic settings. That the issue of social security needs this should be self-evident. The consumption basket of the old is different from those of the young. Indeed the "structural transformation" of an industrialized economy towards a services-based one, happens precisely because the old, whose proportion in the population has grown, consume (certain) services (e.g. health-care) in a higher proportion.

Presumably in a two (or more) sector model, following the reform, some of the adverse effect of the loss of income (the "transfer") to the old would be mitigated by fall in the cost of the goods they consume e.g. health-care. Also, the gain of the increased disposable income of the young would be offset by increased price of the goods that they consume. That is, there are "secondary" effects of the transfer that happen in the period of reform which cannot be captured in a one-sector model. To put it differently, in any period there are intergenerational linkages that work through the market (in addition to a PAYG transfer).

In the international trade context, there is a vast literature on the transfer problem. In particular, various authors have examined the possibility whether the donor could gain and/or the recipients lose from a transfer. There it was found that in a dynamic setting and/or a multi-agent setting such a "transfer paradox" could indeed arise. 
I set up a model with two goods--a pure consumption good and a pure investment good. With the social security reform, there is increases demand for the investment good (as savings rise)--accompanied by a fall in the consumption good demand (as income is transferred from the old, with a marginal propensity to consume of unity, to the young who save a part of their additional income). If the consumption good is labor-intensive, then the wage rate falls.

To answer the question posed in the title of the paper, in such a setting it is possible that everybody alive today would become worse off - the old understandably so but also the young because their wage falls. There would be no one to vote for the reform. This is in spite of the fact that increased capital accumulation makes the future generations better off. The unborn may have liked to vote for reform but they do not have a vote (until they enter the labor force).

The arguments presented in this paper provide a separate reason (other than the absence of insurance markets) as to why there is widespread support for a PAYG social security scheme. Here both the generations currently alive (and voting) would block any attempt to reform it. It is also a possible explanation for why such a reform takes place as part of a macroeconomic or structural package following a crisis, rather than being voted for in normal times.

\section{THE MODEL}

The closed economy consists of overlapping generations of individuals (or households). No individual is altruistically linked to any future generations i.e., there are no bequests or inheritances. Every individual lives for two periods. In the first period of its life (youth) the individual supplies one unit of labor, pays the social security contribution via a payroll tax, and saves for the second period (old age). In old-age, the individual consumes the saving from the first period plus the return on these savings and the receipts from the social security. The social security system is a PAYG one and hence 
balanced budget. The population is growing at a constant rate. We shall study the properties of the model by log-linearizing it around the initial steady state.

The representative household born in time period $t$ maximizes the following utility function

$$
U_{t} \equiv \mathrm{U}\left(C_{t}^{1}, D_{t+1}^{2}\right) \quad \mathrm{t}=0,1,2 \ldots
$$

where $C_{t}^{1} \quad\left(D_{t+1}^{2}\right)$ is the consumption when young (old) of a household born in period t.

The utility function $\mathrm{U}($.$) is increasing and strictly concave in its arguments and$ satisfies the Inada conditions. Both period consumptions are assumed to be normal.

Its lifetime budget constraint is

$$
W_{t}(1-\tau)+\left(\frac{N \tau W_{t+1}}{\chi_{t+1}}\right)=C_{t}^{1}+\left(\frac{1}{\chi_{t+1}}\right) D_{t+1}^{2}
$$

where $W_{t}$ is the wage rate in time period t (in terms of the consumption good, which is the numeraire), $\mathrm{N}$ is the population growth factor i.e., $\mathrm{N} \equiv 1+\mathrm{n}>0$, and $\chi_{t+1}$ the own interest factor on one period consumption loans between $t$ and $t+1$, and. $\tau$ is the payroll tax.We assume that the system is "dynamically efficient" so $\chi_{t+1} \geq N$ (for all t).

In equation (2) we have used the fact that a PAYG scheme pays the proceeds of the payroll tax to the old in that period. Hence the young in period t expect to receive $\tau W_{t+1}$ per worker in their old age. The labor-force will be $\mathrm{N}$ times the current one. This expected future transfer is discounted to date $t$ by using the discount factor $\chi_{t+1}$.

The maximization yields

$$
\frac{\partial U}{\partial C_{t}^{1}}=\chi_{t+1} \frac{\partial U}{\partial D_{t+1}^{2}}
$$


Using equations (2) and (3) we derive the demand functions

$$
\begin{aligned}
& \qquad \begin{aligned}
C_{t}^{1} & =C^{1}\left(W_{t}(1-\tau)+\left(\frac{N \tau W_{t+1}}{\chi_{t+1}}\right), \chi_{t+1}\right) \\
\text { And } \quad D_{t+1}^{2} & =D^{2}\left(W_{t}(1-\tau)+\left(\frac{N \tau W_{t+1}}{\chi_{t+1}}\right), \chi_{t+1}\right)
\end{aligned}
\end{aligned}
$$

The saving function is given by:

$$
S_{t} \equiv W_{t}(1-\tau)-C^{1}\left(W_{t}(1-\tau)+\left(\frac{N \tau W_{t+1}}{\chi_{t+1}}\right), \chi_{t+1}\right)
$$

Savings are assumed to be an increasing function of the real rate of interest. ${ }^{\text {viii }}$ An increase in the interest rate works through three channels-(i) the substitution effect causing a postponement of consumption; (ii) an income effect that would increase consumption in both periods; and (iii) by reducing the present value of future social security receipts it would reduce consumption in both periods.

\section{Firms}

The two goods - a pure consumption good (C) and a pure investment good (I)-are produced under conditions of constant returns to scale using the two inputs, capital and labor. $\mathrm{K}^{\mathrm{C}}\left(\mathrm{K}^{\mathrm{I}}\right)$ is the capital employed in the consumption goods (investment goods) sector. Similarly for $\mathrm{L}^{\mathrm{C}}\left(\mathrm{L}^{\mathrm{I}}\right)$ is the labor employed in the consumption goods (investment goods) sector. All inputs are mobile between sectors instantaneously. The production functions are given by

$$
\begin{aligned}
& C_{t}=\mathrm{F}\left(K_{t}^{C}, L_{t}^{C}\right) \\
& I_{t}=\mathrm{G}\left(K_{t}^{I}, L_{t}^{I}\right)
\end{aligned}
$$


The functions $F($.$) and \mathrm{G}($.$) have positive but diminishing marginal productivities$ and are homogeneous of degree one. They are also assumed to satisfy the Inada conditions.

The consumption good is assumed to be labor-intensive at all relative factor prices. Two justifications are given for assuming this: first, Galor (1992) has shown that in the other case (i.e. when the consumption good is capital-intensive) there is indeterminacy (multiple perfect foresight paths); and, second, in a two-sector model the old spend all their incomes on consumption goods (a large fraction of these are services). These are labor-intensive.

Firms maximize profits with perfect competition in all markets. In equilibrium, the firms set the minimized unit cost equal to the market price of the product

$$
\begin{aligned}
& a_{L C} W_{t}+a_{K C} R_{t}=1 \\
& a_{L I} W_{t}+a_{K I} R_{t}=p_{t}
\end{aligned}
$$

Where $a_{i j}$ is the requirement of the $i^{\text {th }}$ input $(\mathrm{i}=\mathrm{K}, \mathrm{L})$ in the production of the $j^{\text {th }}$ good $(\mathrm{j}=\mathrm{C}, \mathrm{I})$. Note that the $a_{i j}$ 's are functions of the relative factor-prices. ${ }^{\text {ix }}$ The relative price of the investment good in terms of (the numeraire) good $\mathrm{C}$ is given by $\mathrm{p}$ and $\mathrm{R}$ is the (gross) return on capital. We assume capital depreciates completely in the process of production. ${ }^{\mathrm{x}}$ We have in equilibrium $\chi_{t+1}=R_{t+1} / p_{t}$.

\section{Market-Clearing}

In any period, there are two goods markets and two factor markets. By Walras’ Law, if three of these are in equilibrium in any period, then so is the fourth one. We thus have

$$
\begin{aligned}
& a_{L C} C_{t}+a_{L I} I_{t}=1 \\
& a_{K C} C_{t}+a_{K I} I_{t}=k_{t}
\end{aligned}
$$




$$
S_{t}=p_{t} I_{t}
$$

Equations (7a), (7b) and (7c) are the market-clearing conditions for the labor, capital and investment goods markets respectively. In equations (7c) (and in (8a) and (8b), below) we have incorporated the assumption of one hundred per cent depreciation. The variable $C_{t}$ is the production per worker of the consumption good, $I_{t}$ is the output per worker of the investment good and $k_{t}$ is the capital stock per worker (all in time period t).

\section{Dynamics}

The dynamics of the capital stock comes from the fact that the investment good this period is next period's capital stock. Taking into account the growth in the labor force, per worker capital stock evolves as ( $\mathrm{N}$, as noted above, is the population growth factor i.e. $\mathrm{N} \equiv(1+n)$, where $\mathrm{n}$ is its growth rate), we have :

$$
\mathrm{N} k_{+1}=I_{t}
$$

Equation (7c) using (4c)) gives us the other dynamic equation (8b):

$$
W\left(p_{t}\right)(1-\tau)-C^{1}\left(\left(W\left(p_{t}\right)(1-\tau)+\frac{\tau N W\left(p_{t+1}\right) p_{t}}{R\left(p_{t+1}\right)}\right), \frac{R\left(p_{t+1}\right)}{p_{t}}\right)=p_{t} \mathrm{I}\left(p_{t}, k_{t}\right)
$$

\section{Competitive Equilibrium}

Definition: A competitive equilibrium is, given $\tau$ and the initial stock of capital $k(0)$, a sequence of prices and capital stocks $\left(p_{t}, k_{t}\right)_{t=0}^{\infty}$, of wages and the rental rates $\left(W_{t}, R_{t}\right)_{t=0}^{\infty}$, and the consumption pairs $\left(C_{t}^{1}, D_{t+1}^{2}\right)$ such that:

(i) households maximize utility (equations (2) and (3)), 
(ii) firms maximize profits (equations (6a) and (6b)),

(iii) markets clear (equations (7a), (7b) and (7c)),

(iv) And, the capital stock dynamics is given by (8a). ${ }^{x i}$

Existence of equilibrium for the above system is shown in Galor (1992)

\section{The Dynamical System}

Equation (8a) and (8b) are a system of two difference equations expressing $\mathrm{p}_{\mathrm{t}+1}$ and $\mathrm{k}_{\mathrm{t}+1}$ in terms of $\mathrm{p}_{t}$ and $\mathrm{k}_{\mathrm{t}}$ and $\mathrm{d} \tau$.

Write the log-linearized dynamics compactly as $(\mathrm{a} \wedge$ over a variable is the percentage deviation from the steady state):

$$
\left[\begin{array}{l}
\hat{k}_{t+1} \\
\hat{p}_{t+1}
\end{array}\right]=A\left[\begin{array}{l}
\hat{k}_{t} \\
\hat{p}_{t}
\end{array}\right]+H d \tau
$$

The elements of matrix $\mathrm{A}$ and $\mathrm{H}$ are given in Appendix 2. Matrix $\mathrm{A}$ has, under some reasonable assumptions, two positive roots, lying on either side of unity (see Appendix 2).

We can draw a phase diagram (Figure 1) under the assumption that the short run dynamics is Walrasian-a rise $\mathrm{pt}_{t}$ causes an excess supply of the investment good (again see Appendix2).It shows that both $\hat{k}_{t+1}-\hat{k}_{t}=0$ (the KK curve) and $\hat{p}_{t+1}-\hat{p}_{t}=0$ (the IS curve) are downward sloping, with the latter curve being the steeper of the two. The horizontal arrows point away from the KK curve and the vertical arrows point away from the IS curve. The steady state is a saddle point and the stable arm is flatter than the IS line. 


\section{Steady State}

The steady state of this economy is obtained by setting $k_{t+1}=k_{t}=k$ and $p_{t+1}=$ $p_{t}=p$ (a steady state value is denoted without a time subscript) and solving for the other (now time-invariant) variables. From equations (8a) and (8b) we have:

$$
\begin{gathered}
N k=I(p, k) \\
W(p)(1-\tau)-C^{1}\left(\mathrm{~W}(\mathrm{p})(1-\tau)+\left(\frac{N \tau \mathrm{W}(\mathrm{p}) \mathrm{p}}{R(p)}\right), \frac{R(p)}{p}\right)=p I(p, k)
\end{gathered}
$$

\section{A SOCIAL SECURITY REFORM}

Let us analyze a reform defined to be a cut in the payroll tax $(d \tau<0)$ implemented on date 1 i.e. the social security reform is balanced budget. On this date there are old (generation '0') and the young born in period 1. Given the wage rate and the interest rate, savings by generation 1 onwards rise with the social security reform for two reasons: (1) because individuals receive a higher take-home wage in the first period of their lives; and (2) because in their old age they would receive lower transfers from the next generation.

\section{Steady state}

Following a social security reform, the steady state effects of the reform $(\mathrm{d} \tau<0)$ are (from (10a) and (10b)):

$$
\hat{k} / d \tau=-W\left\{1-C_{W}^{1} \Phi\right\} \eta_{I p} /(\Gamma \Delta)<0
$$




$$
\hat{p} / d \tau=W\left(\eta_{I k}-1\right)\left(1-C_{W}^{1} \Phi\right) /(\Gamma \Delta)>0
$$

where $\Delta \equiv\left[\operatorname{pI} \eta_{I p}-\left(1-\eta_{I k}\right)\left\{\eta_{W p}\left(\left(1-C_{W}^{1}\right)(1-\tau) W-\left\{C_{\chi}^{1} \chi-2 C_{W}^{1}\left(\frac{W \tau N}{\chi}\right)\right)+p I\right\}\right] / \Gamma\right.$

is the determinant of (A-I) and $\eta_{i j}$ is an elasticity of the $\mathrm{i}^{\text {th }}$ variable with respect to the $\mathrm{j}^{\text {th }}$ variable (e.g. $\eta_{W p}$ is the elasticity of the wage with respect to the price of investment good) - see the Appendix 1 and 2 for details. In equations (11a) and (11b) to save on notation, we have used $\Phi \equiv(\chi-N) / \chi)\}$; dynamically efficiency implies $\chi>N$ or $\Phi>0$.

Thus, across steady states, the social security reform $(\mathrm{d} \tau<0)$ crowds "in" capital and raises the wage rate—exactly what the proponents of reform say it would do.

\section{Dynamics}

In figure 1 , a fall in $\tau$ moves the IS curve out and the new steady state is at $\varepsilon_{1}$ (the initial steady state was at $\varepsilon_{0}$ ). The system jumps up to $\varepsilon_{01}$ (with $\mathrm{k}_{0}$ predetermined) to the new stable arm, and then adjusts (as capital is accumulated) monotonically along the stable arm to $\varepsilon_{1}$.

Observe the dynamic behavior of $\mathrm{p}_{\mathrm{t}}$, following a cut in $\tau$, shows that first $\mathrm{p}_{\mathrm{t}}$ increases, then it falls along the stable arm. Thus initially the wage rate falls. The take home wage (i.e. net of the payroll tax) rises (loosely, because capital is accumulated).

\section{Welfare}

What is the effect of this on the welfare of a representative member of any generation $t(t=0,1,2 \ldots)$ ? We look at the changes in (i) steady state welfare,(ii) the welfare of the old when the policy is introduced (i.e., the generation born on date 0 which receives a smaller social security check); and (iii) the generation born in period 1 who pay a smaller social security contribution and will receive smaller old-age pensions.

The indirect utility function (from equations (1) and (2) is given by: 


$$
\begin{aligned}
V_{t} & \left(\equiv \operatorname{argmax}_{S_{t}} U\left(\left(W_{t}(1-\tau)-S_{t}\right),\left(\chi_{t+1} S_{t}+N \tau W_{t+1}\right)\right)\right) \\
& =\mathrm{V}\left(W_{t}(1-\tau)+\left(\frac{\tau N W_{t+1}}{\chi_{t+1}}\right), \chi_{t+1}\right)
\end{aligned}
$$

$$
\begin{aligned}
& \text { Or }^{\mathrm{xii}} \\
& \frac{d V_{t}}{V_{W}}=\left[\left((1-\tau) W \eta_{W p} \hat{p}_{t}+\left(\frac{\tau N W}{\chi}\right)\left\{\left(\eta_{W p}-\eta_{R p}\right) \hat{p}_{t+1}+\hat{p}_{t}\right\}-\Phi W d \tau\right)+S\left(\eta_{R p} \hat{p}_{t+1}-\hat{p}_{t}\right)\right]
\end{aligned}
$$

In the steady state the change in utility is:

$$
\frac{\mathrm{dV}}{V_{W}}=\left\{W \eta_{W p}\left(1+2\left(\frac{\tau N W}{\chi(1-\tau)}\right)-\left(\frac{s}{W(1-\tau)}\right)\right)(\hat{p} / d \tau)-\Phi W\right\} d \tau
$$

This is unambiguously positive for $\mathrm{d} \tau<0$. xiii

\section{Period 1}

Thus in the new steady state, with a higher capital stock, welfare rises. But what happens in the earlier periods when the contribution of a higher capital stock is yet to kick in? We now turn to the period when the reform is implemented.

In the period the reform is introduced (period 1), there are the old (generation 0) who receive a smaller old age pension, and the young (generation 1) who pay less to the old but in turn will receive less when they, in turn, are old in period 2.

The jump in $\mathrm{p}_{1}$ is given in figure 1 by the vertical difference between $\varepsilon_{01}$ and $\varepsilon_{0}$

$$
\frac{d \hat{p}_{1}}{d \tau}=\frac{W\left(1-C_{W}^{1} \Phi\right)}{\left(\xi_{U}-1\right) \Gamma}
$$


where $\xi_{U}>1$ is the unstable root of matrix A in equation (10).

The welfare of the old in period 1 (generation ' 0 ') is given by:

$$
V_{0}=R_{1} k_{1}+N \tau W_{1}
$$

Or,

$$
d V_{0}=\left\{\left(R k \eta_{R p}+N \tau W \eta_{W p}\right) \frac{d \hat{p}_{1}}{d \tau}+N W\right\} d \tau
$$

The old receive a double whammy from the social security transfers-a fall in $\tau$ and a fall in $\mathrm{W}_{1}$.It is reasonable to assume that the expression inside the brackets in (15') is positive. So the direct effect of a cut in $\tau$ is not made up by a rise in interest rate (this rise is accompanied by a fall in the wage rate). We assume that the welfare of the old goes down-i.e. we assume the absence of a transfer paradox.

Going back to equation (12), for generation 1

$\frac{d V_{1}}{V_{W}}=\left[\left(\left\{(1-\tau) W \eta_{W p}+\left(\frac{\tau N W}{\chi}\right)-S\right\} \hat{p}_{1}+\left\{\left(\frac{\tau N W}{\chi}\right)\left\{\left(\eta_{W p}-\eta_{R p}\right)+S \eta_{R p}\right\} \hat{p}_{2}-\Phi W d \tau\right)\right]\right.$

In equation (16), as $\mathrm{p}_{1}$ rises, wages fall. A rise in $\mathrm{p}_{1}$ (given $\mathrm{p}_{2}$ ) also lowers the (consumption) real rate of interest $\left(\chi_{t+1} \equiv R_{t+1} / p_{t}\right)$ —this raises the present value of future social security receipts but reduces the interest income on savings. A rise $\mathrm{p}_{2}$ raises the interest on savings but reduces the social security receipts by through a fall in future wage rate and its present value by raising $\mathrm{R}_{2}$. The effect of a cut in $\tau$ is ambiguous theoretically. We turn to examine this for some reasonable parameter values.

\section{NUMERICAL ILLUSTRATIONS}

I provide four examples with different factor shares and elasticities of substitution in production and consumption. I assume an isoelastic utility function 


$$
U\left(C_{t}^{1}, C_{t+1}^{2}\right)=C_{t}^{1^{(1-\sigma)}}+\beta C_{t+1}^{2}{ }^{(1-\sigma)}
$$

The annual rate of interest for illustration is chosen to be $2 \%$ (2.5\% gives the similar results qualitatively). For each period of 30 year length this gives $\Phi=0.26$ (if we had chosen the annual real interest rate to be $2.5 \%, \Phi=0.36$ ).I set $\beta \chi=1$. In Table 1 below, $\theta_{L C}\left(\theta_{L I}\right)$ is the share of wages in sector $C$ (respectively I), $\lambda_{L C}\left(\lambda_{K C}\right)$ the share of employment of L (respectively $\mathrm{K}$ ) in sector $\mathrm{C}, \varepsilon_{i}$ is the elasticity of substitution between factors in sector $\mathrm{I}(\mathrm{i}=\mathrm{C}, \mathrm{I}), 1 / \sigma$ is the intertemporal elasticity of substitution in consumption, and $\xi_{S}$ and, $\xi_{U}$ are respectively the stable and unstable roots for that row. Finally, $\mathrm{dV} / V_{W}$ is the change in welfare (and is of the same sign as $\mathrm{d} \tau$ ).

Table 1

\begin{tabular}{|r|c|c|c|c|c|c|c|c|}
\hline$\theta_{L C}$ & $\theta_{L I}$ & $\lambda_{L C}$ & $\lambda_{K C}$ & $\varepsilon_{C}=\varepsilon_{I}$ & $1 / \sigma$ & $\xi_{S}$ & $\xi_{U}$ & $\mathrm{dV} / V_{W}$ \\
\hline 0.80 & 0.50 & 0.75 & 0.50 & 1 & 2 & 0.54 & 3.32 & $0.12 \mathrm{~d} \tau$ \\
\hline 0.85 & 0.50 & 0.80 & 0.50 & 0.50 & 1.4 & 0.75 & 3.96 & $0.23 \mathrm{~d} \tau$ \\
\hline 0.80 & 0.47 & 0.80 & 0.40 & 0.70 & 2 & 0.53 & 3.57 & $0.16 \mathrm{~d} \tau$ \\
\hline 0.85 & 0.60 & 0.80 & 0.50 & 0.25 & 2 & 0.67 & 2.66 & $0.22 \mathrm{~d} \tau$ \\
\hline
\end{tabular}

\section{CONCLUSIONS}

We have shown the possibility of both generations losing from a social security reform in the period when it is first implemented. This happens, even though when the reform kicks in, capital accumulation and increases wages in the future. To answer the question posed in the title: Possibly no one.

How is it possible that both agents may lose in the initial period of the reform? The fact that the old lose is unsurprising - the interest rate rises but is insufficient to 
compensate for the loss from the transfer. What is surprising is that the young also lose. The intuition is that the direct gain from the transfer is of a second-order whereas the fall in wages is of first order (notwithstanding the subsequent rise in the interest rate). From the discussion in section 3, generation 1 members will save more because of lower social security payments in period 1 and also lower social security receipts in period 2. If they save "a lot", then $\mathrm{p}_{1}$ will move "a lot". As a consequence $\mathrm{W}_{1}$ falls a lot. And this fall in the wage rate cannot be compensated for by the rise in the real rate of interest, and the present value of the reduced social security contributions.

The arguments above have been conducted in a balanced budget setting. A social security fund in reality is infinitely more complex. The paper, at the very least, flags the need to examine a social security reform in a two (or more) sector setting. The other aspects of modelling such a change that have been deliberately switched off in this paper (e.g. elastic labor supply, many period lives, lack of insurance etc.), should be incorporated in such a (more realistic) model. ${ }^{\text {xiv }}$ 


\section{References}

Aaron, Henry J. (2011) “Social Security Reconsidered” National Tax Journal, June, 64, $385-414$

Boldrin, Michele. and Aldo Rustichini (2000) "Political Equilibria with Social Security"

Review of Economic Dynamics 3, 41-78.

Casamatta, Georges., Helmuth. Cremer, and Pierre. Pestieau (2002) “The Political

Economy of Social Security” Scandinavian Journal of Economics 102, 503-522.

Conesa, Juan. C. and Dirk Krueger (1999) "Social Security with Heterogeneous Agents"

Review of Economic Dynamics 2, 757-795.

Conesa, Juan C. and Carlos Garriga, (2008) "Optimal Fiscal Policy in the Design of

Social Security Reforms" International Economic Review 49, 291-318,

Diamond, Peter A. (1965) "National Debt in a Neoclassical Growth Model" American

Economic Review 60, 1126-1150.

Diamond, Peter A. (1977) "A Framework for Social Security Analysis" Journal of Public Economics 8, 275-298.

Diamond, Peter A. (2004) "Social Security” American Economic Review 94, 1-24.

Feldstein, Martin and Jeffrey B. Liebman (2002) "Social Security" in The Handbook of

Public Economics, Volume 4, A.J. Auerbach and M. Feldstein (ed), Elsevier.

Fuster, Luisa, Ayse Imrohoroglu and Selahattin Imrohoroglu (2007). "Elimination of

Social Security in a Dynastic Framework” Review of Economic Studies 74, 113-145.

Galor, Oded(1992) "A Two-sector Overlapping Generations Model: A Global

Characterization of the Dynamical System” Econometrica, 60, 1351-86.

Krueger, Dirk and Felix Kubler, (2006) "Pareto-improving Social Security Reform when

Financial Markets are Incomplete” American Economic Review, 96, 737-755, June.

Nishiyama, Shinichi and Kent Smetters (2007) "Does social security privatization produce efficiency gains?"Quarterly Journal of Economics 122 1677-1719.

Razin, Assaf, Efraim Sadka, and Phillip Swagel (2002) "The Aging Population and the

Size of the Welfare State" Journal of Political Economy 110, no. 4, pp. 900-918

Samuelson, Paul A. (1958) “An Exact Consumption-Loan Model of Interest with or without the Social Contrivance of Money” Journal of Political Economy, 66, 467-482. 
Sinn, Hans-Werner (2000) "Why a Funded Pension System is Useful and Why it is Not Useful” International Tax and Public Finance 7, 389-410.

Solow, Robert M., (2005).”Reflections on Growth Theory” in The Handbook of

Economic Growth, Volume 1, Philippe Aghion and Steven Durlauf (ed.), pages 3-10

Elsevier.

Tabellini, Guido (2000) "A Positive Theory of Social Security” Scandinavian Journal of Economics 102, 523-45. 


\section{APPENDIX 1}

From (A1.1a) and (A1.1b), we can solve for $\hat{W}_{t}$ and $\hat{R}_{t}$ in terms of $\hat{p}_{t}$. We thus have

$$
\begin{aligned}
& \eta_{W p} \equiv \hat{W}_{t} / \hat{p}_{t}=-\theta_{K C} / \Delta \\
& \eta_{R p} \equiv \hat{R}_{t} / \hat{p}_{t}=\theta_{L C} / \Delta
\end{aligned}
$$

where $\Delta \equiv \theta_{L C}-\theta_{L I}=\theta_{K I}-\theta_{K C}$ and $\eta_{\mathrm{ij}}$ is the (partial) elasticity of variable $\mathrm{i}$ with respect to j. From equations (A1.2a) and (A1.2b) we see that $\eta_{W p}$ and $\eta_{R p}$ depend on capital intensities. Given our assumption that the consumption good is labor-intensive, $\Delta>0$. And hence by the Stolper-Samuelson Theorem, $\eta_{W p}<0, \eta_{R p}>1$.

Similarly by logarithmically differentiating (6a), (6b) and (6c) we have

$$
\begin{aligned}
& \lambda_{L C} \cdot \hat{C}_{t}+\lambda_{L I} \cdot \hat{I}_{t}=\left[\hat{W}_{t}-\hat{R}_{t}\right]\left[\lambda_{L C} \cdot \theta_{K C} \cdot \varepsilon_{C}+\lambda_{L I} \cdot \theta_{K I} \cdot \varepsilon_{I}\right] \\
& \lambda_{K C} \cdot \hat{C}_{t}+\lambda_{K I} \cdot \hat{I}_{t}=\hat{k}_{t}-\left[\hat{W}_{t}-\hat{R}_{t}\right]\left[\lambda_{K C} \cdot \theta_{L C} \cdot \varepsilon_{C}+\lambda_{K I} \cdot \theta_{L I} \cdot \varepsilon_{I}\right]
\end{aligned}
$$

where $\lambda_{i j}$ is the share of sector $\mathrm{j}$ in the total employment of input $\mathrm{i}$ and $\varepsilon_{j}$ is the elasticity of substitution between inputs in the $j^{\text {th }}$ industry.

From equations (A1.3a) and (A1.3b), we have the Rybczinski effects (which depend on assumed capital intensities)

$$
\begin{aligned}
& \eta_{I k} \equiv \hat{I}_{t} / \hat{k}_{t}=\lambda_{L C} / \Omega>0 \\
& \eta_{C k} \equiv \hat{C}_{t} / \hat{k}_{t}=-\lambda_{L I} / \Omega<0
\end{aligned}
$$

where $\Omega \equiv \lambda_{L C}-\lambda_{K C}>0$ (by assumption).

From (A1.3a) and (A1.3b), we have the supply elasticities (which are independent of capital intensities)

$$
\eta_{I p} \equiv \hat{I}_{t} / \hat{p}_{t}=\left\{\lambda_{L C} \lambda_{K C} \varepsilon_{I}+\left(\lambda_{L C} \lambda_{K I} \theta_{L I}+\lambda_{K C} \lambda_{L I} \theta_{K I}\right) \varepsilon_{C}\right\} /(\Delta \Omega) \geq 0
$$




\section{APPENDIX 2}

Matrices $\mathrm{A}$ and the vector $\mathrm{H}$ in equation (9) are given by

$$
\begin{gathered}
A \equiv\left[\begin{array}{cc}
\eta_{I k} & \eta_{I p} \\
-p I \eta_{I k} / \Gamma & {\left[\left(1-C_{W}^{1}\right)(1-\tau) W \eta_{W p}+\left\{C_{\chi}^{1} \chi-C_{W}^{1}\left(\frac{\tau N W}{\chi}\right)\right\}-p I\left(1+\eta_{I p}\right)\right] / \Gamma}
\end{array}\right], \\
\mathrm{H} \equiv\left[\begin{array}{c}
0 \\
-W\left(1-C_{W}^{1} \Phi\right) / \Gamma
\end{array}\right] \\
\Gamma \equiv \eta_{R p}\left\{C_{\chi}^{1} \chi-C_{W}^{1}\left(\frac{\tau N W}{\chi}\right)\right\}+C_{W}^{1}\left(\frac{\tau N W}{\chi}\right) \eta_{W p}<0 \\
\text { where } C_{j}^{1} \equiv \partial C_{t}^{1} / \partial j_{t} \text { is the derivative with respect to variable } \mathrm{j}(\mathrm{j}=\mathrm{W}, \chi) .
\end{gathered}
$$

All the elements of matrix A are positive. The two roots are $\xi_{S}$ and $\xi_{U}$.

$$
\begin{gathered}
\operatorname{Tr} A=\xi_{S}+\xi_{U}=a_{11}+a_{22}>0 \\
\operatorname{Det} A=\xi_{S} \xi_{\mathrm{U}}=\eta_{I k}\left[\left(1-C_{W}^{1}\right)(1-\tau) W \eta_{W p}+\left\{C_{\chi}^{1} \chi-C_{W}^{1}\left(\frac{\tau N W}{\chi}\right)\right\}-p I\right] / \Gamma>0
\end{gathered}
$$

Now

$$
(\operatorname{Tr} A)^{2}-4 \operatorname{Det} A>0
$$

(Proof: All the elements of matrix A are positive. Hence

$$
\left.\left(a_{11}+a_{22}\right)^{2}-4\left\{a_{11} a_{22}-a_{12} a_{21}\right\}=\left(a_{11}-a_{22}\right)^{2}+4\left(a_{12} a_{21}\right)>0 \boldsymbol{\square}\right)
$$

So the (two positive) roots are real.

The requirement

$$
\begin{gathered}
1-\operatorname{Tr} A+\operatorname{Det} A<0 \\
1-\operatorname{Tr} A+\operatorname{Det} A= \\
1-\left(a_{11}+a_{22}\right)+a_{11} a_{22}-a_{21} a_{12}
\end{gathered}
$$




$$
\left(1-a_{11}\right)\left(1-a_{22}\right)-a_{21} a_{12}
$$

A "high enough" value of $\eta_{I p}$ is a sufficient condition to deliver this (requiring "high" elasticities of substitution in production). If $\eta_{I p}$ is "low", then the Rybczinski elasticity $\eta_{I k}$ has to be high.

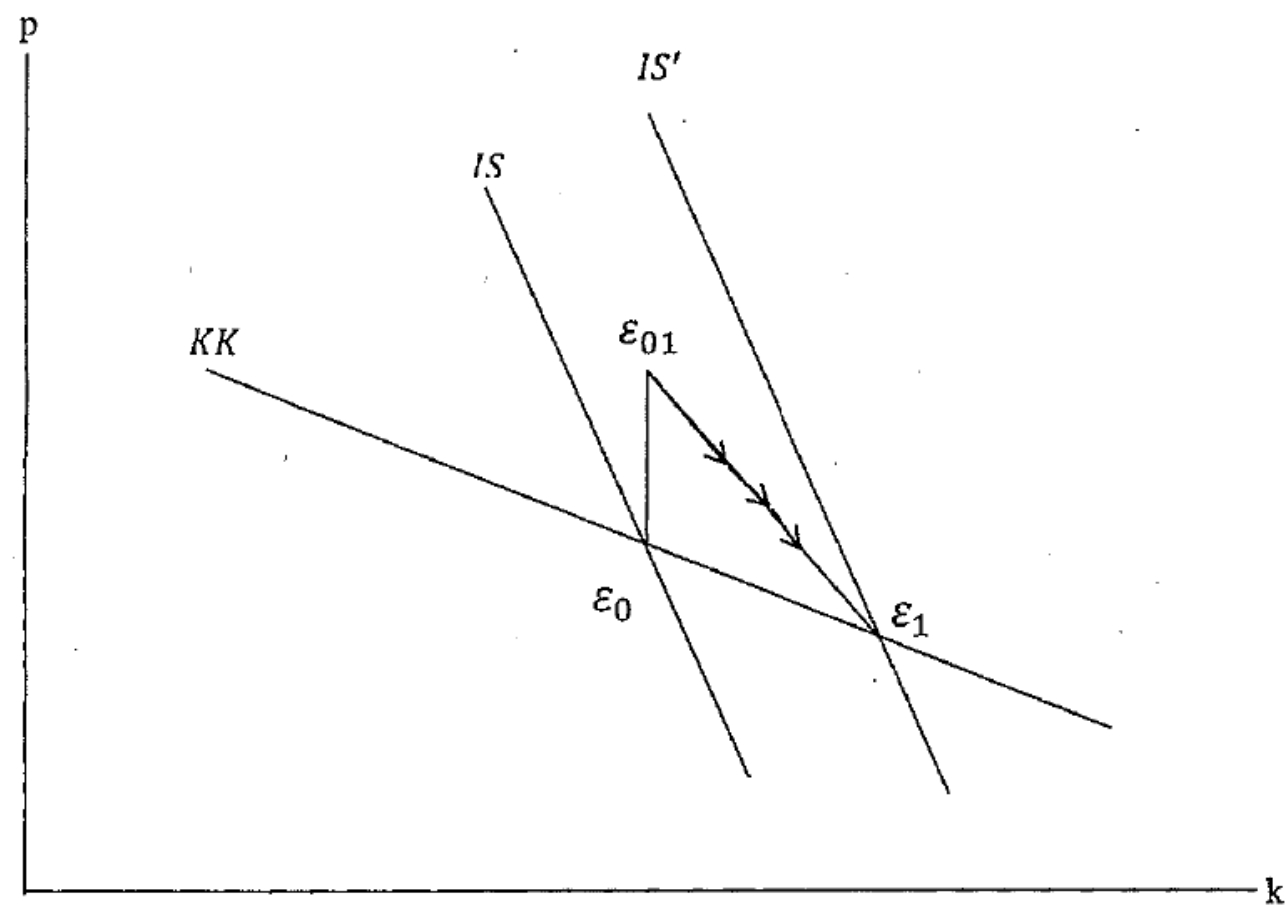

Figure 1 


\begin{abstract}
i Similarly for Germany since 1957 with the "dynamic" pension system, there is provision for disability, pensions for widows and orphans in addition to the contributor receiving a pension in retirement.

ii Three sample quotations: "While incomplete financial markets can provide a rationale for social security, it is also well known that in a general equilibrium model a PAYGO social security system crowds out private savings and thus capital formation, and therefore leads to lower wages for future generations." Krueger and Kubler (2006) p. 738; "The unfunded public pension system provides insurance against mortality and individual income risks for which insurance through private markets is either unavailable or difficult due to moral hazard and other reasons. At the same time, the unfunded system distorts the saving and labor supply decisions and imposes a deadweight cost on the society. When these two sets of effects of social security are evaluated in economic models, it is almost always the case that the unfunded system has an overall welfare cost on the households." Fuster et al. (2007), p.113; and "(When) wages are not insurable, privatization reduces efficiency by about $\$ 2,400$ per future household despite improving labor supply incentives. This loss occurs even though privatization substantially increases the welfare of those born in the long run by increasing the capital stock...” (Nishiyama and Smetters (2007) p.1677).

iii In analyzing the reform various authors have highlighted the role of insurance, altruism and labor supply. ${ }^{\text {iv }}$ See Sinn (2000) for a good analysis of the proposed reform.

${ }^{v}$ Fuster et al (2007) point out the importance of intergenerational linkages and the need for a high labor supply elasticity.

vi،....if the social security system is of the PAYG type, and the rate of interest is higher than the rate of population growth, private saving is more attractive, at least for a young worker.” (Casamatta et al (2000) p. 504)
\end{abstract}

vii A recent survey reported that in 2010:“'On the $75^{\text {th }}$ anniversary of Social Security, public support for the program remains exceedingly high.” And: "Although they are far from claiming Social Security retirement benefits, younger Americans are very supportive of the program. Nine in ten adults under age 30 believe Social Security is an important government program.” http://www.aarp.org/work/social-security/info-08-2010/social_security_75th.html

viii This is not always assumed in the literature. See e.g. Casamatta et al (2000) where they assume the contrary.

${ }^{\text {ix }}$ We rule out Leontief technologies, where the $a_{i j}$ 's are constant, by assumption (because if the consumption good is labor-intensive, Leontief technologies do not give dynamic stability).

${ }^{x}$ This is an innocuous assumption and can be dispensed with easily. But this is not a bad assumption for a model where a single period corresponds to about 35 to 40 years!

${ }^{x i}$ For the existence of a steady state with a positive capital stock $\tau$ cannot be very "large".

xiiWe have used the properties of the indirect utility function: $\partial V_{t} / \partial W_{t}=\frac{\partial U_{t}}{\partial C_{t}^{1}}$, and $\partial V_{t} / \partial \chi_{t+1}=\mathrm{S} \frac{\partial U_{t}}{\partial D_{t+1}^{2}}$.

xiiiThis because

$\eta_{W p} W(1-\tau)\left[1-\left(\frac{S}{(1-\tau) W}\right)+2\left(\frac{\tau N}{\chi(1-\tau)}\right)\right]<0$

${ }^{\text {xiv }}$ The argument in this paper, however, seems to work against the proposal of postponing retirement as a panacea for the viability of the social security system. This is shown in a paper available from the author on request. 